\title{
ANALISIS MANAJEMEN RISIKO DI UNIT SIRKULASI PERPUSTAKAAN FAKULTAS $X$
}

\author{
Ratih Surtikanti \\ Laboratorium Manajemen Informasi dan Dokumen, Program Vokasi Universitas Indonesia, \\ ratihvokasi@gmail.com
}

Diterima : 12 Desember 2014

Layak Terbit : 3 Januari 2015

\section{Abstrak}

Peran manajemen rekod seringkali baru disadari oleh sebuah organisasi atau seseorang ketika terjadi masalah atau kesulitan yang hanya dapat diatasi jika ada dokumen yang berisi informasi yang diperlukan. analisa manajemen rekod yang efektif maka organisasi dapat membenahi sistem manajemen rekod yang ada sesuai dengan bidang prioritas yang paling penting bagi organisasi. Dengan adanya pembenahan sistem manajemen rekod dalam organisasi diharapkan pada masa yang akan datang tidak akan menghadapi masalah baik dalam bidang hukum, keuangan, sejarah maupun admistratif.

Kata Kunci: manajemen rekod,manajemen risiko,tata kelola perpustakaan

\begin{abstract}
The role of records management is often only realized by an organization or a person when there are problems or difficulties that can only be overcome if there is a document that contains the necessary information. analysis of effective record management so organizations can reorganize the existing record management system in accordance with the most important priority for the organization. With the improvement in the organization's records management system is expected in the foreseeable future will not encounter any problems either in the fields of law, finance, as well as the administrative history.
\end{abstract}

Keywords:. Record management, risk management, library governance

\section{PENDAHULUAN}

\section{Latar Belakang}

Manajemen resiko adalah bagian integral dari sebuah proses manajemen. Manajemen resiko adalah istilah yang diterapkan pada metode yang logis dan sistematis dari identifikasi, analisa, penilaian, perlakuan, pengawasan dan resiko komunikasi yang berhubungan dengan sejumlah kegiatan, fungsi atau proses dalam cara yang memungkinkan organisasi untuk memperkecil kerugian dan memperbesar kesempatan (The Institute of Risk Management : 2002).

Dalam kaitannya dengan manajemen rekod, maka penerapan manajemen resiko mengarah pada pengurangan resiko dengan mengambil keputusan untuk membuat dan menyimpan rekod-rekod tertentu. Rekod-rekod tersebut dibuat untuk memenuhi kebutuhan akuntabilitas, pembuktian, dan informasi pendukung dalam menjalankan kegiatan.

Sebagai bagian dari sebuah proses manajemen maka manajemen risiko dapat diterapkan pada sebuah organisasi, unit kegiatan atau pun sebuah program.

Proses penereapan manajemen resiko terdiri dari beberapa tahap. Dua tahap elemen utama proses manajemen resiko adalah (The Institute of Risk Management :2002): (a) Membangun konteks. Tahap ini membangun konteks strategis, organisasi dan manajemen resiko di mana sisa proses akan berlangsung. Kriteria terhadap di mana resiko akan dinilai 
mulai dibangun dan struktur analisa ditetapkan. (b)Mengenali resiko. Mengenali apa, mengapa dan bagaimana sesuatu dapat terjadi adalah lanjutan dari analisa.

\section{METODE}

Pendekatan yang digunakan dalam penelitian ini adalah pendekatan kualitatif. Kajian ini menekankan pada studi kasus dalam upaya memahami risiko yang Data primer diperoleh peneliti melalui observasi dan wawancara terhadap informan seperti staf perpustakaan tentang pekerjaan. Sedangkan Data sekunder dalam penelitian ini diperoleh melalui kegiatan studi pustaka, berupa penelusuran dokumen yang memuat fakta-fakta, artikel atau referensi, serta bahan-bahan lain yang berhubungan dengan kegiatan di unit sirkulasi Perpustakaan X.

\section{HASIL DAN PEMBAHASAN}

\section{Membangun Konteks}

Dalam pembahasan berikut ini akan diuraikan bagaimana kedua tahapan di atas diterapkan pada Unit Kegiatan Sirkulasi di Perpustakaan Fakultas X.

Unit Kegiatan Sirkulasi di Perpustakaan Fakultas X merupakan bagian dari organisasi perpustakaan fakultas yang mempunyai visi dan misi yang sejalan dengan visi dan misi Perpustakaan. Misi Perpustakaan adalah mendukung misi Fakultas sebagai salah satu unsur pelaksana kegiatan Tri Darma Perguruan Tinggi, dalam bidang pendidikan, penelitian dan pengabdian masyarakat. Perpustakaan merupakan salah satu sarana penunjang pelaksanaan misi Fakultas dengan penekanan pada kegiatan pengadaan dan pelayanan bahan pustaka dan informasi yang diperlukan dalam pencapaian misi Tri Darma Perguruan Tinggi.

Kedudukan Unit Sirkulasi dalam organisasi Perpustakaan Fakultas X dapat dilihat dalam bagan struktur di bawah ini.

\section{Bagan Struktur Organisasi Perpustakaan Fakultas X}

Unit ini melakukan fungsi primer perpustakaan berupa Fungsi Pelayanan Pengguna.

Dalam rangka menjalankan fungsinya, Unit ini melakukan kegiatan sebagai berikut:

- kegiatan pendaftaran anggota, yang terdiri dari pendaftaran anggota baru dan perpanjangan keanggotaan, serta pembuatan surat keterangan bebas pinjam untuk mahasiswa yang akan mengambil ijazah.

- penyediaan sarana sirkulasi,

- kegiatan peminjaman,

- kegiatan layanan baca,

- kegiatan foto kopi,

- kontrol sirkulasi,

- layanan referensi

Kebijakan yang diterapkan Unit Sirkulasi dalam menjalankan fungsinya adalah memberikan akses seluas-luasnya kepada koleksi dan informasi yang dimiliki Perpustakaan di samping memastikan bahwa keselamatan dan keberadaan koleksi dapat dijaga. Aturan dan program dibuat mengaju pada pelaksanaan misi perguruan tinggi, yaitu 
pendidikan, penelitian, dan pengabdian masyarakat dengan mempertimbangkan aspek keselamatan dan keberadaan koleksi. Keberhasilan luaran dari kegiatan Unit ini dilihat dari banyaknya mahasiswa dan pemakai lain yang memanfaatkan layanan perpustakaan dengan melihat data statistik yang dibuat. secara baik dengan pemakai layanan. Secara umum pemakai layanan terdiri dari mahasiswa, dosen, staf umum, dan masyarakat umum. Disamping itu juga kualitas Unit Sirkulasi ditentukan oleh tingkah laku lingkungan internal dan ekstertal Unit Sirkulasi.

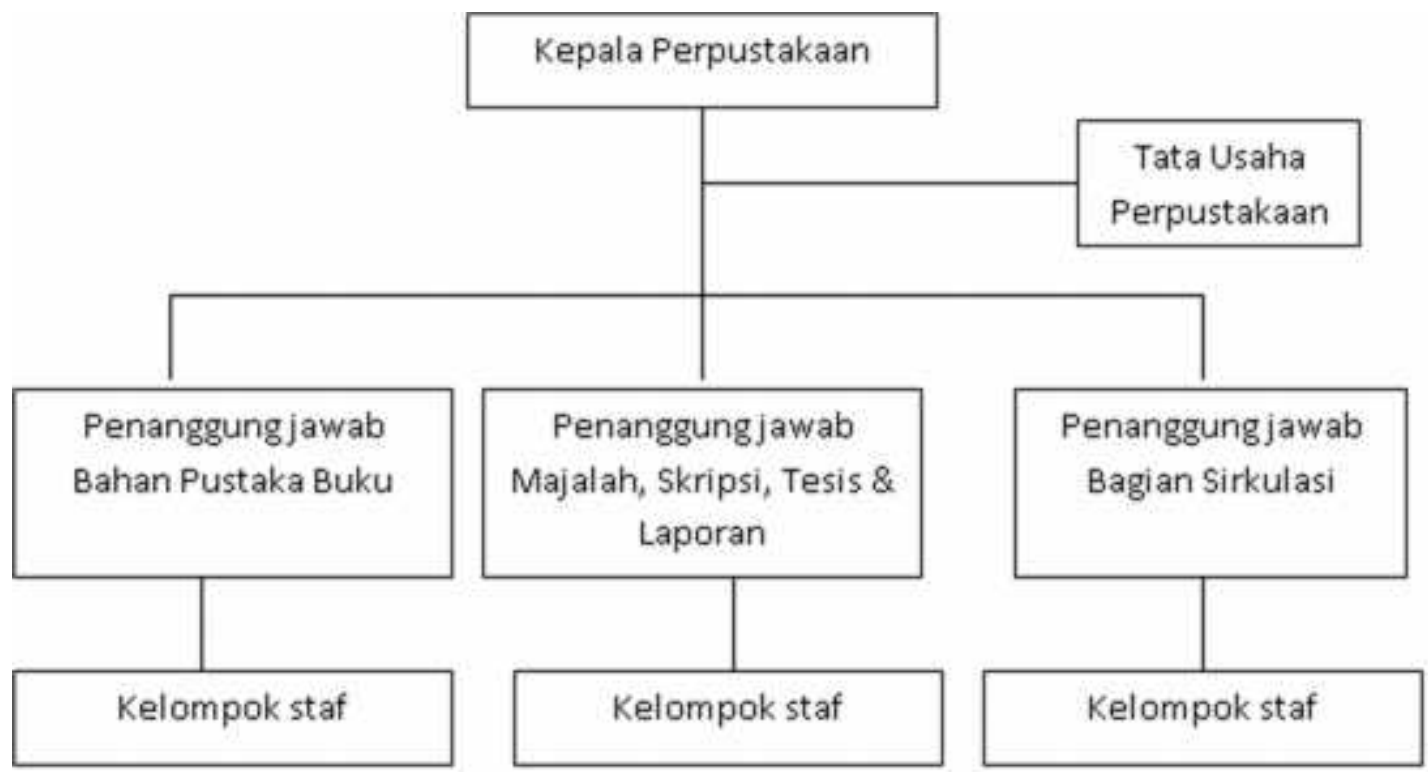

Gambar 1. Bagan Struktur Organisasi Perpustakaan Fakultas X Sumber : Survey, diolah oleh penulis ,2015

Data statistik ini meliputi: Data pengunjung perpustakaan per bulan; Data peminjaman koleksi per bulan; Data pengunjung luar per bulan; Data permintaan fotokopi per bulan.

Sebagaimana umumnya sebuah fungsi layanan maka kekuatan dan kelemahan Unit Sirkulasi berkisar antara kualitas staf sebagai ujung tombak layanan, kualitas sumber daya koleksi, dan kualitas sistem layanan yang mudah dan cepat.

Keseluruhan kualitas itu sangat menentukan bagaimana Unit Sirkulasi dapat berinteraksi
Beberapa hal di antaranya adalah bagaimana staf Unit lain bekerja, bagaimana pelaksanaan kebijakan organisasi terhadap aturan yang sudah dibuat, disamping seberapa besar dukungan dari Dekanat dalam menjalankan program-program yang dibuat oleh Perpustakaan Unit ini.

\section{Tabel Identifikasi Risiko}

Berdasarkan konteks organisasi Unit Sirkulasi Perpustakaan Fakultas X maka berikut ini akan dicoba dibuatkan satu tabel Identifikasi 
Risiko. Tabel ini adalah suatu metode cara meringkas resiko yang muncul di organisasi dengan menggunakan template identifikasi resiko. impak yang mempengaruhi pembentukan citra lembaga di dalam komunitas yang dilayaninya.

Tabel 1 Identifikasi Risiko

\begin{tabular}{|c|c|c|c|c|c|c|c|}
\hline \multirow[b]{2}{*}{$\begin{array}{c}\text { Sumber-sumber } \\
\text { Resiko }\end{array}$} & \multicolumn{7}{|c|}{ Bidang Dampak } \\
\hline & Aset & Citra & Biaya & $\begin{array}{l}\text { Jadual/ } \\
\text { waktu }\end{array}$ & Kinerja & Komunitas & $\begin{array}{c}\text { Tingkahlaku } \\
\text { organisasi }\end{array}$ \\
\hline $\begin{array}{l}\text { Hubungan } \\
\text { komersial \& legal }\end{array}$ & & $\sqrt{ }$ & & & $\sqrt{ }$ & & \\
\hline Ekonomi & $\sqrt{ }$ & & & & & & $\sqrt{ }$ \\
\hline $\begin{array}{l}\text { Tingkahlaku } \\
\text { manusia }\end{array}$ & & $\sqrt{ }$ & & $\sqrt{ }$ & $\sqrt{ }$ & & $\sqrt{ }$ \\
\hline Bencana alam & & & & & & & \\
\hline Situasi politik & & & & & & & $\sqrt{ }$ \\
\hline $\begin{array}{l}\text { Teknologi/isu -isu } \\
\text { teknis }\end{array}$ & & $\sqrt{ }$ & & & $\sqrt{ }$ & & \\
\hline $\begin{array}{l}\text { Aktivitas \& kontrol } \\
\text { manajemen }\end{array}$ & & $\sqrt{ }$ & & & $\sqrt{ }$ & & $\sqrt{ }$ \\
\hline Aktifitas individu & & & & & & & \\
\hline
\end{tabular}

Sumber : Institute of risk management, diadaptasi oleh penulis 2015

Tujuan dari kegiatan ini adalah mengenali apa, mengapa dan bagaimana sesuatu dapat terjadi yang dapat menimbulkan risiko bagi organisasi. Tabel ini akan menggambarkan bagaimana sumber-sumber risiko tertentu mempengaruhi satu atau beberapa bidang dalam sebuah unit atau organisasi. Pembahasan di bawah ini akan memberikan penjelasan bagaimana tiap sumber resiko mempengaruhi bidang impak tertentu. Sebagai sebuah unit yang berhubungan langsung dengan pemakai maka hal paling menonjol yang dapat dikenali adalah bidang

\section{Hubungan komersial \& legal terhadap} Citra organisasi

Salah satu kegiatan Unit Sirkulasi adalah memberikan Surat Bebas Pinjam kepada mahasiswa yang akan mengambil ijazah. Surat ini merupakan bukti bahwa mahasiswa tersebut telah menyelesaikan kewajibannya di perpustakaan. Untuk melakukan kegiatan ini Unit harus memiliki data peminjaman dari mahasiswa yang bersangkutan, baik di lingkungan fakultas maupun universitas. Ketidakmampuan Unit melakukan kegiatan ini secara baik akan merugikan citra lembaga 
di dalam komunitas pemakainya karena dianggap mempersulit proses pengurusan kelulusan mereka. Di samping itu juga kegagalan Unit, dalam bentuk pemberian Surat tersebut pada mahasiswa yang belum menyelesaikan kewajibannya di universitas, dapat merugikan citra lembaga di lingkungannya. Perpustakaan dapat dinilai tidak cakap dalam melaksanakan kewajiban bersama.

\section{Hubungan komersial \& legal terhadap Kinerja}

Deskripsi kerja dan aturan yang berlaku di sebuah Unit kerja akan menjadi dasar dalam melakukan interaksi dengan bagian lain dalam lingkungan internal dan eksternalnya. Kepastian hak dan kewajiban diantara pihak yang saling berinteraksi akan sangat mempengaruhi kinerja sebuah unit. Salah satu contoh klasik di perpustakaan perguruan tinggi adalah tidak jelasnya aturan sirkulasi terhadap staf pengajar. Tidak ada aturan atau sanksi yang jelas yang diberikan pada staf pengajar yang tidak mengembalikan atau menghilangkan koleksi, meskipun unit mempunyai catatan tentang keberadaan koleksi tersebut. Kondisi ini seringkali menimbulkan rasa tidak puas staf Unit perpustakaan yang bertugas.

\section{Ekonomi terhadap Aset}

Secara umum kondisi ekonomi akan mempengaruhi hampir seluruh bidang kehidupan. Jika diperkecil lingkupnya pada Unit Sirkulasi maka kondisi ekonomi akan mempengaruhi asset yang dimiliki.
Berkurangnya alokasi dana pada kegiatan sirkulasi akan mempengaruhi jenis koleksi yang dapat digunakan untuk mencapai tujuan pelayanan. Kondisi ekonomi komunitas pemakai yang rendah dan harga koleksi buku yang mahal juga turut meningkatkan jumlah kehilangan dan pengrusakan koleksi. Keberadaan data mengenai tingkat kehilangan buku atau format usulan yang dibuat oleh pemakai dapat digunakan Unit untuk mengajukan program yang akan menjelaskan kondisi asset yang mereka miliki dan memperkuat usulan perbaikan yang diajukan.

\section{Ekonomi terhadap Tingkah laku organisasi}

Kemampuan lembaga dalam beroperasi dan melaksanakan berbagai kegiatan jelas sangat dipengaruhi oleh kondisi ekonomi berupa kebijakan pengalokasian dana pada kegiatan perpustakaan. Kebijakan sentralisasi pendanaan pernah dilakukan dan ternyata mengalami banyak hambatan menyebabkan organisasi harus merubah beberapa kebijakan pengadaan sumber dananya. Dalam beberapa hal ketika organisasi merubah pola kebijakan dalam rangka menyelesaikan masalah yang dihadapinya, maka organisasi sering harus mengalami penolakan dari lingkungan ekternal yang mempengaruhinya. Keberadaan laporan keuangan yang dibuat oleh Unit atau tingkat kebutuhan yang tinggi dari pemakai dapat digunakan sebagai bukti dan pembenaran terhadap beberapa kebijakan yang diambil lembaga dalam rangka beradaptasi dengan kondisi ekonomi yang terjadi 


\section{Situasi politik terhadap Tingkah laku organisasi}

Pergantian pimpinan baik pada tingkat internal, maupun pada lingkungan fakultas dan dekanat sangat mempengaruhi tingkah laku organisasi. Seringkali pergantian pimpinan menyebabkan pergantian kebijakan. Misalnya dalam hal keanggotaan perpustakaan, perubahan dalam hal pendanaan anggota akan mempengaruhi jenis program yang dapat diberikan. Catatan atau laporan tingkat penggunaan layanan perpustakaan dapat digunakan lembaga sebagai dasar pemikiran dalam rangka beradaptasi dengan kebijakan baru yang berlaku.

\section{Teknologi/isu -isu teknis terhadap Citra organisasi}

Sebagai ujung tombak pelayanan, maka luaran yang cepat dan nyaman merupakan hal yang sangat diinginkan oleh komunitas pemakai. Salah satu cara yang ditempuh untuk memberikan layanan yang cepat dan nyaman adalah dengan menerapkan teknologi sebagai alat bantu. Disamping itu teknologi tidak dapat dipungkiri juga sering kali dapat meningkatkan citra sebuah lembaga. Pada Unit Sirkulasi dengan adanya teknologi yang akan mempercepat layanan akan langsung dirasakan oleh pemakai. Oleh karena itu penerapan teknologi yang tepat sasaran dapat mempengaruhi citra organisasi. Salah satu rekod yang dapat digunakan dalam rangka penerapan teknologi di unit layanan adalah dengan melihat beban kerja berdasarkan data statistik yang dibuat.

\section{Teknologi/isu -isu teknis terhadap Kinerja}

Salah satu hal yang ditawarkan oleh teknologi adalah penyelesaian pekerjaan dengan lebih cepat dan tepat. Sebagai sebuah unit yang berfungsi primer memberikan layanan maka penerapan teknologi akan sangat mempengaruhi kinerja dari Unit ini. Apakah akan menjadi lebih baik atau tidak sangat bergantung pada pemilihan jenis teknologi yang akan diambil.

\section{Aktivitas \& kontrol manajemen terhadap Citra organisasi}

Sebagai Unit yang langsung berhubungan dengan komunitas pemakai maka penerapan standar perilaku dan aturan yang dijalankan sangat mempengaruhi citra organisasi. Apakah tiap kelompok pemakai mendapatkan hak dan kewajiban yang sama. Apakah setiap pengunjung mendapatkan perlakuan yang sama baiknya. Lemahnya kontrol manajemen terhadap hal tersebut jelas akan merugikan citra organisasi. Perlu ada dokumen yang memuat hak dan kewajiban staf dan komunitas pemakai secara jelas, agar dapat dilakukan kontrol yang adil dan berimbang terhadap layanan yang diberikan.

\section{Aktivitas \& kontrol manajemen terhadap Kinerja \\ Kinerja staf layanan sangat penting dalam menjalankan fungsi layanan di perpustakaan. Sebuah unit yang ujung tombaknya berupa layanan antar personal sangat membutuhkan kontrol manajemen untuk menjaga kualitasnya. Keberadaan data statistik yang}


dihasilkan oleh unit ini dapat digunakan untuk menilai kinerja oleh pihak manajemen. Untuk melakukan ini juga perlu ada dokumen yang memuat hak dan kewajiban staf dan komunitas pemakai secara jelas, agar dapat dilakukan kontrol yang adil dan berimbang terhadap layanan yang diberikan.

\section{Aktivitas \& kontrol manajemen terhadap Tingkah laku organisasi}

Keberadaan dokumen yang memuat kebijakan layanan organisasi juga sangat dibutuhkan dalam mengurangi risiko konflik antara kontrol manajemen dan tingkah laku organisasi. Kejelasan kebijakan akan sangat memudahkan kedua pihak mengambil keputusan dan melakukan penilaian.

\section{PENUTUP}

\section{Simpulan}

Peran manajemen rekod seringkali baru disadari oleh sebuah organisasi atau seseorang ketika terjadi masalah atau kesulitan yang hanya dapat diatasi jika ada dokumen yang berisi informasi yang diperlukan. Demikian juga apabila ada masalah yang muncul akibat kegiatan organisasi yang tidak didokumentasikan dengan benar.

Keperluan ini bisa sifatnya hukum, keuangan, sejarah, atau administratif. Dengan menyadari bahwa manajemen rekod yang baik dalam sebuah organisasi merupakan prasyarat untuk mencapai akuntabilitas melalui analisa risiko yang harus dihadapi oleh organisasi. Melalui analisa manajemen rekod yang efektif maka organisasi dapat membenahi sistem manajemen rekod yang ada sesuai dengan bidang prioritas yang paling penting bagi organisasi. Dengan adanya pembenahan sistem manajemen rekod dalam organisasi diharapkan pada masa yang akan datang tidak akan menghadapi masalah baik dalam bidang hukum, keuangan, sejarah maupun administratif.

\section{DAFTAR PUSTAKA}

McKemmish, Sue. The Smoking Gun: Recordkeeping and Accountability. http://www.sims.monash.edu.au/rcrg/publications/.html. Diakses tgl 19 Oktober 2002 Yesterday, Today and Tomorrow: A Continuum of Responsibility http://www.sims.monash.edu.au/rcrg/publications/recordscontinuum/smckp2.html. Diakses tgl 19 Oktober 2002

Iacovino, Livia. The Nature of the Nexus Between Recordkeeping and the Law. http://www.sims.monash.edu.au/rcrg/publications/.html. Diakses tgl 19 Oktober 2002

The Institute of Risk Management. A Risk Management Standard. London. 2002. www.theirm.org/knowledge-and-resources/risk-management-standards.asp. Diakses tgl 19 Oktober 2002 